\title{
Stage IIB Testicular Cancer AJCC v8
}

National Cancer Institute

\section{Source}

National Cancer Institute. Stage IIB Testicular Cancer A/CC V8. NCI Thesaurus. Code C140235.

Stage IIB includes: (Any pT/TX, N2, M0, S0); (Any pT/TX, N2, M0, S1). TX: Testicular cancer in which the primary tumor cannot be assessed. N2: T esticular cancer with metastasis with a lymph node mass larger than $2 \mathrm{~cm}$ but not larger than $5 \mathrm{~cm}$ in greatest dimension; or more than five nodes positive, none larger than $5 \mathrm{~cm}$; or evidence of extranodal extension of tumor. M0: Testicular cancer without evidence of distant metastasis. S0: Marker study levels within normal limits. S1: LDH less than $1.5 \times \mathrm{N}$ and hCG (mlU/mL) less than 5,000 and AFP ( $\mathrm{ng} / \mathrm{mL}$ ) less than 1,000. N indicates the upper limit of normal for the LDH assay. (AJCC 8th ed.) 